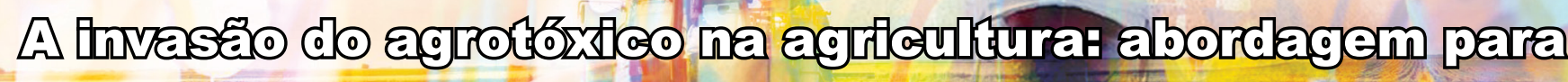

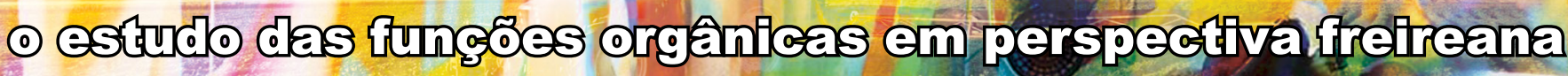 da oducacto numa oscolla pirbilica
}

Anne Caroline C. Santos, Amélia B. Souza, Thales S. Silva e Maria Clara P. Cruz

Nesta pesquisa foi estudado o contexto do tema social agrotóxico, e o conteúdo de funções orgânicas, utilizando o referencial freireano adaptado à educação formal. O procedimento metodológico foi constituído nos três momentos pedagógicos de Delizoicov ajustado às ideias de Paulo Freire. A problematização ocorreu através de uma pesquisa de sondagem com os agricultores da região em que a escola está inserida, gerando debate com os educandos em torno de um vídeo sobre o temático Agrotóxico. Na organização de conhecimento, foi ministrada uma aula sobre haletos orgânicos e funções nitrogenadas, desenvolvendo a contextualização. Já na aplicação de conhecimento, identificaram-se os principais grupos funcionais presentes nos agrotóxicos que são utilizados naquela região. Foram desenvolvidas produções textuais como dado analítico. Para o diagnóstico dos dados, a análise textual discursiva foi utilizada, o que permitiu verificar que a perspectiva freireana transformou a realidade concreta em que os estudantes vivem pela emancipação social, cultural e política. Nesse sentido, reconhecê-los como sujeitos de uma outra pedagogia e dialogar através de suas identidades e histórias fez toda a diferença. Então, o conhecimento escolar se articulou com a realidade e a educação se estabeleceu como elemento de transformação através da alfabetização científica sobre a química dos agrotóxicos.

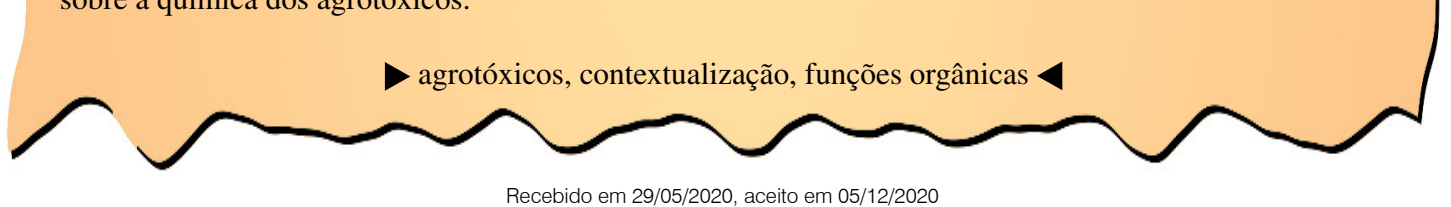

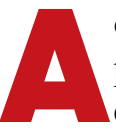
o longo da história da civilização, o ser humano procurou meios para se desenvolver em sociedade e, nessas circunstâncias, o meio ambiente foi alvo de inúmeros impactos, comprados pela ideia da modernização. Nas cadeias produtivas, os agrotóxicos ganham cada vez mais o status de "modernos" e "poderosos" pelo agronegócio que, por sua vez, é patrocinado através dos discursos da influência do "Agro", como "pop", "tech", como "tudo" (Souza, 2019).

As mudanças que vem ocorrendo sobre a saúde e o ambiente nas comunidades rurais do Brasil devem ser consideradas. De acordo com Castro Neto et al. (2010), estudos comprovam que os agrotóxicos contaminam os alimentos, o ambiente e causam danos à saúde humana, sendo que "a

A seção "Relatos de Sala de Aula" socializa experiências e construções vivenciadas nas aulas de Química ou a elas relacionadas. contaminação química associada aos processos produtivos se caracteriza como um dos mais complexos problemas de saúde pública e ambiental no país" (Peres, 2009, p. 2002).

Anualmente são usados no mundo aproximadamente 2,5 milhões de toneladas de agrotóxicos por ano. O consumo anual no Brasil, de acordo com o IBGE, tem sido superior a 300 mil toneladas, com aumento no consumo de agrotóxicos de $700 \%$ nos últimos quarenta anos. A utilização de produtos químicos para o con-
trole de pragas, doenças e ervas daninhas mais que dobrou em dez anos (IBGE, 2015).

Agrotóxicos, defensivos agrícolas, praguicidas, pesticidas, venenos ou remédios de plantas: são inúmeras as denominações relacionadas ao grupo de substâncias químicas utilizadas no controle de pragas e doenças de plantas (Peres e Moreira, 2003). Tradicionalmente, eram classificados de acordo com o tipo de praga que combatem, denominando-os 
inseticidas (repele insetos), fungicidas (evita fungos), herbicidas (controla plantas invasoras), além de reguladores de crescimento, desfoliantes (combate às folhas indesejadas) e dissecantes (Silva e Fay, 2004). Com o advento da Constituição Federal de 1988, todos esses termos foram substituídos por agrotóxicos, a fim de tornar evidente a toxicidade dessas substâncias (FUNASA, 1998).

Analisando a singularidade das conexões que cada pessoa estabelece em função de suas experiências e saberes, torna-se necessário promover processos de aprendizagem através do tema agrotóxico em estabelecimentos de ensino (Kraushaar e Roskosz, 2016; Balica, 2016; Cavalcanti et al., 2010, Braibante e Zappe, 2010). As escolas rurais devem contemplar as necessidades dos camponeses, pois estabelecem uma relação direta com o ambiente (Pessanha ${ }^{1}$ et al., 2002, apud Corrêa, 2017). Os alunos, filhos de agricultores, devem atuar como multiplicadores de conhecimentos sobre a importância da utilização correta de agrotóxicos e dos problemas que causam à saúde do homem e do ambiente, evidenciando os discursos às boas práticas agrícolas.

Uma maneira de aproximar a disciplina de Química com o temático agrotóxico é através do ensino da identificação das funções orgânicas mistas presentes em muito deles. O aluno, assim, compreende quimicamente quem é cada um (Braibante e Zappe, 2010, Cavalcanti et al., 2010). Dessa forma, é possível interligar o conteúdo a uma função social da disciplina (Santos e Schnetzler, 1996). Com isso, o educando é alfabetizado cientificamente para discutir questões interdisciplinares numa pedagogia crítica e se torna um cidadão reflexivo, capaz de interferir e, se preciso, modificar o meio social no qual se encontra inserido (Soares e Júnior, 2018, Abreu et al., 2015). Algumas metodologias podem ser utilizadas para esse fim, como, por exemplo, jogos didáticos (Mello et al., 2018), metodologias análogas (Lima e Mozzer, 2019), estudos de caso (Abreu et. al, 2015), enfoque em Ciência, Tecnologia e Sociedade (Kraushaar e Roskosz, 2016) e metodologia dos três momentos pedagógicos de Delizoicov transpostos das ideias de Paulo Freire (Simões e Alves, 2018).

Nesse sentido, esta pesquisa irá trabalhar com a última delas. Segundo Francisco Jr., Ferreira e Hartwig (2008) "transpor as ideias de Freire à educação formal é problemático, visto que a teoria freiriana foi desenvolvida, basicamente, a partir da educação informal” (p. 35, 2006). A transposição para a educação formal foi feita por Delizoicov (1982, 2008), que estruturou três momentos pedagógicos (3 MPs): problematização inicial; organização do conhecimento e aplicação do conhecimento. A primeira delas é o processo de investigação: nesse momento, educando e educador procuram, no "universo" do aluno e da sociedade em que ele vive, as palavras e temas centrais que estejam vinculados a sua vida, possibilitando a contextualização. Na segunda etapa, educando e educador trabalham os temas, procurando o significado social, tomando assim consciência deles e da conexão com o mundo em que vivem, por meio de uma visão científica. Por fim, na última etapa o aluno e o professor buscam enxergar além de uma primeira visão dos temas, buscando uma perspectiva crítica do mundo e dos fatos, seguindo para a transformação do contexto vivenciado (Francisco Jr. et al., 2008).

A partir desse contexto fático e político, e tendo em vista a importância do tema para as escolas do campo (ou escolas públicas que tenham alunos que auxiliam/aprendem na lavoura dos pais) e suas implicações no mundo rural, é importante falar sobre os agrotóxicos, proporcionando práticas que despertem a atenção dos estudantes, e que possam ser utilizadas por professores de química em salas de aula, como situações-problema cotidianas (Lima e Mozzer, 2019; Simões e Alves, 2018; Mello et al., 2018; Andrade, 2018; Abreu et al., 2015; Cassal et al., 2013; Moraes et al., 2011). Os agrotóxicos integram em demasiada primazia a realidade dos discentes nessas escolas, pois o planejamento nas lavouras de monoculturas influi diretamente na qualidade de vida de todos que estão sendo afetados pelo uso indiscriminado destas substâncias (Corrêa, 2017).

Portanto, considerando a conjuntura dessa intervenção e com o objetivo de criar o processo de apreensão do tema social ao conteúdo funções orgânicas e suas faces no ambiente rural, foi desenvolvida a presente pesquisa.

\section{Procedimentos Metodológicos}

O tema foi trabalhado com vinte e três educandos do $3^{\circ}$ ano do Ensino Médio do Colégio Estadual Doutor João de Melo Prado situado no centro do município Divina Pastora SE. Os alunos foram designados pela letra "A" seguido por um número que variou de $1-23$. A escolha foi motivada pela localização geográfica do colégio, rodeado por plantações, sendo a principal prática econômica do município a agricultura de cana-de-açúcar e milho.

Os pesquisadores iniciaram o processo de determinar o tema gerador observando os educandos, a comunidade em que eles vivem e o contexto do uso de agrotóxico no local. Nesse sentido, foram analisados o entorno da escola e as situações vivenciadas pelos educandos. Para isso, foram feitas uma conversa com o professor regente, entrevistas com agricultores da comunidade e a contabilização de filhos de agricultores na turma selecionada. Assim, foi escolhida a turma e o tema gerador agrotóxicos. A partir disso, foi iniciado o procedimento metodológico baseado nos três momentos pedagógicos (3 MPs) de Delizoicov (1982), fundamentados na transposição das ideias de Paulo Freire sobre a alfabetização de jovens e adultos. Delizoicov (2008) ressalta que, para a compreensão e adoção de práticas educativas balizadas pelo referencial freireano, o conceito de tema gerador 
configura-se como elemento importante. Assim, foram utilizadas oito aulas para a realização desta pesquisa, com duração de cinquenta minutos cada uma. O Quadro 1 mostra a organização das atividades desenvolvidas.

A problematização foi dividida em três partes: inicialmente foi feita sondagem da cultura local de cinco agricultores, com as seguintes questões: Você faz uso de agrotóxico? Qual o agrotóxico mais utilizado? Possui o hábito de ler o rótulo dos agrotóxicos? Sabe o que é classe toxicológica? Utiliza EPI’s quando vai usar agrotóxico? O que fazem com as roupas que são usadas na aplicação dos agrotóxicos? Onde faz o descarte dos agrotóxicos? Na segunda etapa, foi feito um debate a respeito do documentário $O$ veneno está na mesa (15 min) do cineasta Silvio Tendler, que alerta para os problemas causados aos trabalhadores, à população e ao ambiente pelo uso indiscriminado de agrotóxicos no país. Por fim, protagonizamos um debate.

$\mathrm{Na}$ organização do conhecimento foi ministrada uma aula sobre funções nitrogenadas e haletos, pois eram as funções orgânicas desconhecidas pelos alunos. Após a aula, o educador discutiu com os discentes sobre o agrotóxico mostrado no vídeo, o DDT, a fim de identificar as funções orgânicas. Além disso, os alunos foram sondados quanto ao uso de agrotóxico por meio das seguintes questões: 1. Quem de vocês já utilizou agrotóxicos nas plantações? 2. Cite um tipo de agrotóxico usado nas lavouras por vocês ou seus pais. Essas duas questões visam trazer o contexto do dia a dia dos alunos para sala de aula e correlacioná-lo com o conteúdo químico.

No momento de aplicação do conhecimento, a turma foi dividida em quatro grupos, de acordo com a cor da classe toxicológica dos agrotóxicos que os trabalhadores locais utilizavam. Nessa aula, foi distribuído um pincel atômico, uma tabela das funções orgânicas e cartolinas em cores de acordo com a faixa do rótulo do defensivo, regulamentada pela ANVISA. Cada grupo pôde aplicar seus conhecimentos nos assuntos de química, identificando as funções orgânicas nos agrotóxicos. Posteriormente, foi apresentado aos educandos um vídeo de entrevista produzido pela pesquisadora com um agricultor local que sobrevive do cultivo da cana-de-açúcar.

Por fim, para avaliar a aprendizagem, os discentes desenvolveram uma produção textual intitulada "A temática agrotóxico facilitou a compreensão das funções orgânicas e os riscos de uso inadequado desses produtos químicos?". Esses dados foram analisados através da análise textual discursiva (ATD), que visa produzir novas teorias durante o processo de ensino-aprendizagem (Moraes e Galiazzi, 2006).

\section{Resultados e Discussão}

Antes de iniciar a intervenção didática na turma, foi realizada uma pesquisa sondagem com cinco agricultores da região de Divina Pastora, para saber em que cultura os
Na organização do conhecimento foi ministrada uma aula sobre funções nitrogenadas e haletos, pois eram as funções orgânicas desconhecidas pelos alunos. Após a aula, o educador discutiu com os discentes sobre o agrotóxico mostrado no vídeo, o DDT, a fim de identificar as funções orgânicas. alunos estão inseridos. Podemos sintetizar que os produtores rurais ali inseridos possuem menor grau de escolaridade, e todos eles utilizam agrotóxicos considerados tóxicos, a saber: hexazinoma- D, acefato, diuron, glifosato, atrazina e U 46. Não têm a prática de ler os rótulos e bulas dos defensivos, tampouco detêm conhecimentos sobre as classificações toxicológicas dos defensivos. Descartam incorretamente as embalagens, e não fazem uso de EPI's. As roupas usadas após as aplicações dos agrotóxicos são lavadas juntamente com as demais roupas dos familiares. Nesse sentido, os resultados da entrevista apresentaram dados preocupantes relativos às práticas de risco adotadas em decorrência da falta de manejo e orientações devidas.

É importante a educação como prática da liberdade por meio do universo de temas que estão ligados às relações homem-mundo. Através dessa averiguação é que se chegam às palavras geradoras, dando origem aos temas geradores (Freire, 2008). A entrevista com os produtores

Quadro 1: Organização das atividades em etapas e recursos utilizados

\begin{tabular}{|c|c|c|}
\hline MP & Aula & Atividades \\
\hline Problematização Inicial & $1^{\circ}-3^{\circ}$ & $\begin{array}{l}\text { 1. Gravação em áudio e exposição de entrevistas de agricultores } \\
\text { locais; } \\
\text { 2. Documentário "O Veneno está na mesa"; disponível em https:// } \\
\text { www.youtube.com/watch?v=8RVAgD44AGg\&t=1419s } \\
\text { 3. Roda de conversa para debate sobre o documentário gravado } \\
\text { via áudio. }\end{array}$ \\
\hline Organização do Conhecimento & $4^{\circ}-6^{\circ}$ & $\begin{array}{l}\text { 1. Aula sobre funções nitrogenadas e haletos orgânicos; } \\
\text { 2. Descarte de embalagens de agrotóxicos; } \\
\text { 3. Identificação das funções orgânicas e classificação toxicológica } \\
\text { dos agrotóxicos que os alunos conhecem. }\end{array}$ \\
\hline Aplicação do Conhecimento & $7^{\circ}$ e $8^{\circ}$ & $\begin{array}{l}\text { 1. Documentário com o agricultor do município; } \\
\text { 2. Desenvolvimento da produção textual. }\end{array}$ \\
\hline
\end{tabular}

Fonte: Elaborado pelo autor (2019). 
rurais favoreceu esse aspecto da pesquisa, e permitiu identificar os tipos de agrotóxicos mais utilizados naquela região. De posse do contexto local do uso de agrotóxicos, foi feito o primeiro momento pedagógico de 15 minutos com a turma. Ele teve início com um vídeo $O$ veneno está na mesa, provocando uma roda de conversa para debate entre os 17 estudantes presentes sobre os problemas que o uso desregrado dos venenos causa à saúde e ao ambiente. $\mathrm{O}$ debate foi gravado via áudio.

Quando foi perguntado aos educandos "Por que será que muitos chamam agrotóxico de veneno?" um deles respondeu: "porque é um remédio muito forte que rapidinho as pragas morrem e não fica nem cobra nas plantações". Percebe-se que o estudante, bem como a maioria deles, não tem noção formada sobre os sérios danos que o agrotóxico pode causar à saúde humana e ao ambiente. Podem chegar a provocar mortes entre os agricultores que estão aplicando o defensivo, e também malefícios aos consumidores que irão ingerir o alimento infectado. Temos, até então, apenas experiências do senso comum e a reprodução dos costumes familiares.

Outra pergunta foi: "O que são agrotóxicos?" De acordo com as respostas dadas pelos educandos, notam-se as mais variadas nomeações na definição de agrotóxicos. A resposta de um dos alunos mostra que tem conhecimento sobre as pragas que aparecem no cultivo da cana-de-açúcar, e comenta sobre a necessidade do uso dos defensivos como forma para aumentar as produções, e com qualidades satisfatórias para mercado. Novamente, prevalece o senso comum dos discentes:

São remédios utilizados contra pragas e pestes que invadem as plantações. A cigarrinha é uma peste que dá na cana, quando coloca o veneno elas morre. E assim, para ter mais qualidade e muita quantidade na cana, que estão sendo plantados pra vender. (A5)

Quando indagados: "Quem de vocês já utilizou agrotóxicos nas plantações?", os educandos responderam que nunca utilizaram; então questionamos àqueles, entre eles, quais eram filhos de camponeses ou que conheciam alguém que sobrevivia da "roça", e os alunos negaram relação. Este resultado foi inesperado, tendo em vista a pesquisa inicial para definição do tema gerador. Mesmo com isso, continuamos o desenvolvimento da intervenção didática.

Os estudantes começaram a ter noções dos males causados pelos agrotóxicos à saúde humana e ao ambiente, depois de terem assistido ao vídeo $O$ veneno está na mesa, conforme a fala do A8: “...acho que sim, no vídeo mostrou que um tipo de agrotóxico aí, matou tanta gente na guerra e até hoje nasce gente defeituosos. Essas coisas devem ser muito braba" (A8). Alguns se mostraram indignados com a possibilidade de estarem comendo "veneno" nos alimentos. Porém, anteriormente não se faziam esses questionamentos.

Percebemos que havia entre os alunos um conhecimento prévio e comum sobre agrotóxicos, mas torna-se evidente a necessidade de aquisição de conhecimento científico, vez que as informações apontadas estavam desconexas, errôneas e pouco sistematizadas. Então, um diálogo diretivo com o educador pode permitir ao educando um conhecimento do seu pensar ingênuo em relação ao seu conhecimento prévio, superando sua situação de oprimido (Freire, 2008).

Para a segunda etapa da pesquisa, foi ministrada uma aula que abordava funções nitrogenadas e haletos orgânicos, dado que os educandos ainda não conheciam essas funções. Durante essa aula, identificamos os grupos funcionais existentes na molécula do agrotóxico DDT, pois foi uma das partes do vídeo que mais chamaram a atenção dos discentes. O Quadro 2 mostra as funções orgânicas que foram identificadas em sala de aula.

Algo muito relevante foi que os alunos se desinibiram através da empatia com a autora da pesquisa, que afirmou ser filha de um pedreiro, explicando que ele não usava equipamento de proteção individual (EPI) e voltava para casa machucado. Com efeito, dez discentes levantaram as mãos revelando que seus pais eram agricultores, que os ajudavam no campo e se desculparam por não ter relatado inicialmente. Freire (2006) adverte sobre a necessidade de aprender as situações da vivência, também denominadas de contradições existenciais, do mundo dos educandos, pois são nestas que estão presentes os temas geradores de debate que, contribuindo para uma mudança comportamental, sinalizam

Quadro 2: Principais funções orgânicas presentes no agrotóxico DDT

\begin{tabular}{|c|c|c|c|}
\hline Agrotóxico & Estrutura Química & Função Orgânica & Nomenclatura IUPAC \\
\hline DDT & Haleto & $\begin{array}{c}\text { t,1,1-tricloro }-2,2 \text { di (p clorofenil) } \\
\text { etano }\end{array}$ \\
\hline
\end{tabular}

Fonte: Elaborado pelo autor (2019). 
para uma reprodução reflexiva e crítica do conhecimento, tornando efeito a partir da vivência.

Esse fato remete à ideia de que os educandos têm dificuldades de aceitarem suas origens, o que Freire denomina de contradição existencial. Talvez para eles sua origem não seja socialmente um sucesso. Foi nesse momento, com a identidade pessoal estabelecida, que ocorreu o real sentido da pesquisa para eles e o quanto poderiam intervir com os pais. Nesse contexto, foi explanada aos estudantes a definição de EPI, porque durante a problematização verificamos que os discentes não sabiam seu significado e da importância em se usar equipamento de segurança no manejo dos defensivos agrícolas.

Quando indagados novamente: "Quem de vocês já utilizou agrotóxicos nas plantações?", dentre os dezessete alunos que estavam no debate, quinze relataram que seus vizinhos e amigos faziam uso do mesmo. Com as respostas obtidas a esse questionamento, podemos notar que os estudantes comprovaram que a comunidade escolar se encontra rodeada de plantações, as quais fazem uso de agrotóxicos, o que justifica a necessidade da pesquisa.

Durante o desenvolvimento da Organização do Conhecimento, foi perguntado aos alunos um tipo de agrotóxico que eles ou os pais utilizavam nas plantações. Um dos estudantes verificou no celular a foto do agrotóxico " $U$ 46 BR", registrada durante o trabalho rural com o pai. A partir desse momento, pode-se observar que esse estudante também não tinha o hábito de ler o nome do agrotóxico que manuseava na lavoura com seus familiares. Acerca desse defensivo, foram levantados pontos com os educandos sobre sua composição química $(2,4 \mathrm{D})$, que estava presente no herbicida tóxico denominado "agente laranja", utilizado como desfolhante na Guerra do Vietnã. Tudo isso fez sentido com a exibição do vídeo na aula anterior, fazendo um paralelo entre história, química e saúde.

O segundo ponto foi esclarecer aos discentes sobre a importância e os prejuízos que a falta de leitura do rótulo do agrotóxico pode provocar à saúde humana e ao ambiente. Foi abordado na aula que, quando uma substância apresenta propriedades nocivas ou perigosas, trata-se de uma substância tóxica e sua capacidade potencial é a toxidade. Consequentemente, a toxidade dos agrotóxicos desenha o perigo para a saúde das pessoas e ao ambiente. Por isso, todos os rótulos dos defensivos apresentarão toxidade que a ANVISA classifica em quatro classes de danos à saúde humana. Nos rótulos desses produtos estão as cores que representam cada classe, facilitando a identificação do grau de toxidade de determinado defensivo (Quadro 3).

Foi esclarecido aos estudantes que os rótulos e bulas dos agrotóxicos revelariam as classes de acordo com o tipo de praga, as cores das classes de toxidade, o armazenamento apropriado dos defensivos, descarte correto das embalagens, o uso devido dos EPI's e a descontaminação devida das vestimentas usadas após as aplicações.

Após essa conscientização, os alunos procuraram na internet qual é a estrutura química do agrotóxico "U 46
Quadro 3: Classes toxicológicas e suas respectivas cores de faixa

\begin{tabular}{|c|c|c|}
\hline Classe & Toxidade & $\begin{array}{c}\text { Cor da Faixa de } \\
\text { Rótulo e Bula }\end{array}$ \\
\hline I & Extremamente Tóxico & Faixa vermelha \\
\hline II & Altamente Tóxico & Faixa amarela \\
\hline III & Moderamente Tóxico & Faixa azul \\
\hline IV & Pouco Tóxico & Faixa verde \\
\hline
\end{tabular}

Fonte: Elaborado pelo autor (2019).

BR" que, posteriormente, foi desenhada no quadro branco para os alunos identificarem as funções orgânicas presentes no defensivo agrícola. Logo em seguida, foi comentado com os estudantes que, quando compramos os agrotóxicos, necessariamente devem ser lidos as bulas e os rótulos para obter as informações de como fazer uso deles corretamente. Nessa aula, os discentes aprenderam que os rótulos fornecem informações importantes e que precisam de atenção, antes e na hora de usar os produtos. As características do "U 46 BR" são mostradas no Quadro 4.

Quadro 4: Identificação das funções orgânicas e informações presente no rótulo do agrotóxico "U 46 BR"

\begin{tabular}{|c|c|}
\hline Agrotóxico & U 46 BR \\
\hline Fórmula Estrutural & Aaleto, Éter e Ácido Carboxílico \\
\hline Funções Orgânicas $2-(2,4-$ diclorofenoxi $)$ \\
\hline Nomenclico
\end{tabular}

Fonte: Elaborado pelo autor (2019).

Com essa aula, evidenciamos que nenhum aluno tinha conhecimento informado dos agrotóxicos ou da importância de ler os rótulos e bulas. Ao final da aula, fizeram comentários a esse respeito:

Eu ajudo meu pai nas plantações da cana-de-açúcar, mas a gente não sabia que os venenos que a gente compra na cidade, vem dizendo tudo isso no rótulo que vocêfalou não. (A13)

Meu esposo trabalha ajudando a um moço agricultor nas plantações de cana-de-açúcar, mas não usa tudo isso aí de proteção não, que a senhora falou. Só usa mesmo chapéu por causa do sol, a bota por causa de cobra e as vezes um macacão e eu lavo tudo na lavanderia de lá de casa. A gente nunca soube que não podia. (A 5) 
Os alunos ficaram espantados quando souberam dessas informações, e sentiram-se motivados a debater sobre as implicações que os "venenos" podem ter em seus familiares. A aula buscou envolver os estudantes, não apenas no entendimento do conteúdo de funções orgânicas, mas também em relacionar os diversos fatores que o manuseio incorreto dos agrotóxicos pode provocar. A conclusão obtida pelos educandos nessa aula é corroborada por Moro (2008, p. 83) que faz o seguinte comentário:

O uso indiscriminado de agrotóxicos no Brasil, assim como em outros países da América Latina, resulta em níveis severos de poluição ambiental e intoxicação humana, uma vez que grande parte dos agricultores desconhece os riscos a que se expõem $e$, consequentemente, negligenciam algumas normas básicas de saúde e segurança no trabalho.

No desenvolvimento da aplicação do conhecimento, buscou-se empregar o conhecimento do qual o estudante vem se apropriando, analisar e interpretar as situações que foram propostas na problematização inicial, utilizando diferentes recursos pedagógicos para o momento. Assim, na aula seguinte a turma foi dividida em quatro grupos conforme descrito na metodologia, de acordo com a cor da classe toxicológica do agrotóxico que os produtores rurais usam naquela região. Cada grupo recebeu uma cartolina, caneta piloto, a fórmula química do defensivo, uma tabela de funções orgânicas e uma lista de como agir diante dos agrotóxicos.

No decorrer do desenvolvimento do trabalho dos discentes, dois grupos sentiram dificuldades em identificar as funções orgânicas presentes nos agrotóxicos, e os outros dois conseguiram detectar com mais facilidade, observando a tabela de funções orgânicas. Cada grupo ficou responsável em ir à frente e apresentar para a turma: o nome do agrotóxico, fórmula estrutural, os grupos funcionais identificados nele, a classe, cultura utilizada, classificação toxicológica, sintomas e sinais clínicos que podem ocorrer após o uso do defensivo, segundo o rótulo que eles buscaram na internet.

O primeiro grupo, responsável pelo defensivo da classe de toxidade com faixa de cor vermelha na embalagem, expôs à frente da turma os grupos funcionais presentes na fórmula estrutural do agrotóxico Hexazinona-D, de classificação I (extremamente tóxico). Os sintomas e sinais clínicos observados após o uso, segundo o rótulo. são: "Alterações hepáticas, irritação da mucosa respiratória e podem ocorrer náuseas, vômito e diarreia...". No Quadro 5, encontra-se o que o grupo apresentou sobre o agrotóxico com maior toxicidade.

O segundo grupo ficou responsável pelo agroquímico da classe de toxidade com faixa de cor amarela na embalagem, e apresentou à turma os grupos funcionais presentes na fórmula estrutural do agrotóxico Diuron, de classificação II (Altamente Tóxico). Os sintomas e sinais clínicos após o uso desse defensivo, de acordo com o rótulo pesquisado, são: "Ansiedade, agitação, confusão mental, ataxia, depressão de centros cardiorrespiratórios, convulsões e coma..." O Quadro 6 ilustra o que o grupo apresentou.

O terceiro grupo ficou responsável pelo insumo da classe de toxidade com faixa de cor azul na embalagem, e apresentou à turma os grupos funcionais presentes na fórmula estrutural do agrotóxico Acefato, de classificação III (Medianamente Tóxico). Entre os sintomas e sinais clínicos após o uso desse defensivo, conforme o rótulo encontrado, destacam-se: "depressão, ansiedade, irritabilidade, comprometimento da memória, concentração...”. No Quadro 7 encontra-se o que o grupo apresentou.

O último grupo ficou responsável pelo agrotóxico da classe de toxidade com faixa de cor verde na embalagem, e apresentou à frente da turma os grupos funcionais presentes na fórmula estrutural do herbicida Glifosato, de

Quadro 5: Grupo 1 da cartolina vermelha

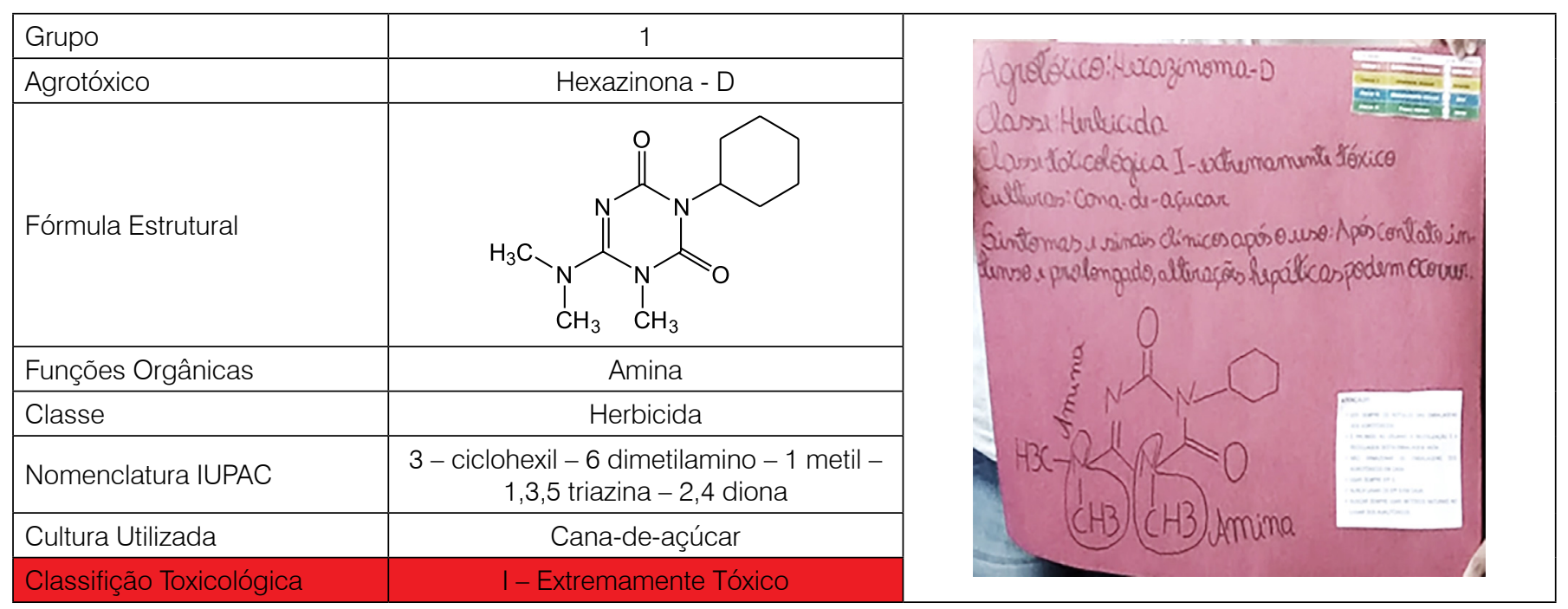

Fonte: Elaborado pelo autor (2019). 
Quadro 6: Grupo 2 da cartolina amarela

\begin{tabular}{|c|c|c|}
\hline Grupo & 2 & 20 \\
\hline Agrotóxico & Diuron & \\
\hline \multicolumn{3}{|l|}{ Fórmula Estrutural } \\
\hline Classe & Herbicida & 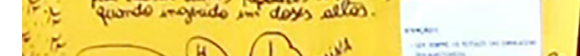 \\
\hline Nomenclatura IUPAC & 3- (3,4-diclorofenil) - 1,1-dimetilureia & $\left.f^{\prime}\right)^{, N} 0=0$ \\
\hline Cultura Utilizada & Cana-de-açúcar & (3) 0 \\
\hline Classifição Toxicológica & II - Altamente Toxico & 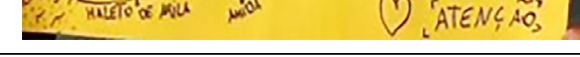 \\
\hline
\end{tabular}

Fonte: Elaborado pelo autor (2019).

Quadro 7: Grupo 3 da cartolina azul

\begin{tabular}{|l|c|}
\hline Grupo & Acefato \\
\hline Agrotóxico & $\mid$ \\
\hline Fórmula Estrutural & \\
\hline Funções Orgânicas & Amida \\
\hline Classe & Inseticida \\
\hline Nomenclatura IUPAC & O,S-dimetilacetilfosforamidotioato \\
\hline Cultura Utilizada & Cana-de-açúcar e milho \\
\hline Classifição Toxicológica & III - Medianamente Tóxico \\
\hline
\end{tabular}
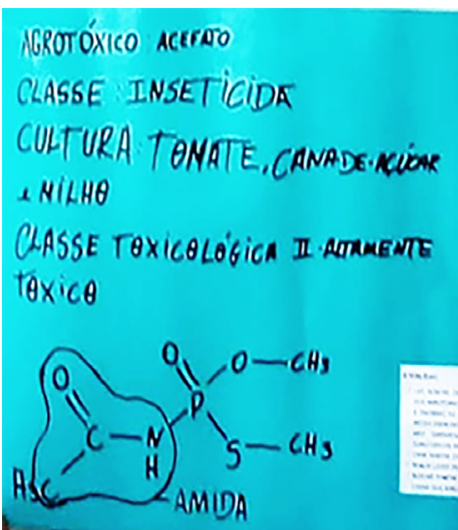

Fonte: Elaborado pelo autor (2019).

classificação III (Medianamente Tóxico). Os sintomas e sinais clínicos após o uso desse defensivo, segundo o rótulo, são: "Irritante dérmico e ocular, pode causar danos hepáticos e renais, quando ingerido em doses altas". No Quadro 8, encontra-se o que o grupo apresentou.

Trabalhar os conteúdos de forma contextualizada com temática que envolve a realidade dos educandos proporciona motivação por parte deles em aprender o conteúdo de funções orgânicas, bem como o engajamento acerca dos problemas que giram em torno do tema. Após as apresentações dos grupos, os trabalhos foram expostos na parede da sala de aula.

Dando continuidade à pesquisa, os alunos foram

Quadro 8: Grupo 4 da cartolina verde

\begin{tabular}{|l|c|}
\hline Grupo & Glifosato \\
\hline Agrotóxico & Ácido carboxílico e amina \\
\hline Funções Orgânicas & Herbicida \\
\hline Classe & $\mathrm{N}$ - (fosfonometil) glicina \\
\hline Nomenclatura IUPAC & Cana-de-açúcar e milho \\
\hline Cultura Utilizada & IV - Pouco Tóxico \\
\hline Classifição Toxicológica &
\end{tabular}

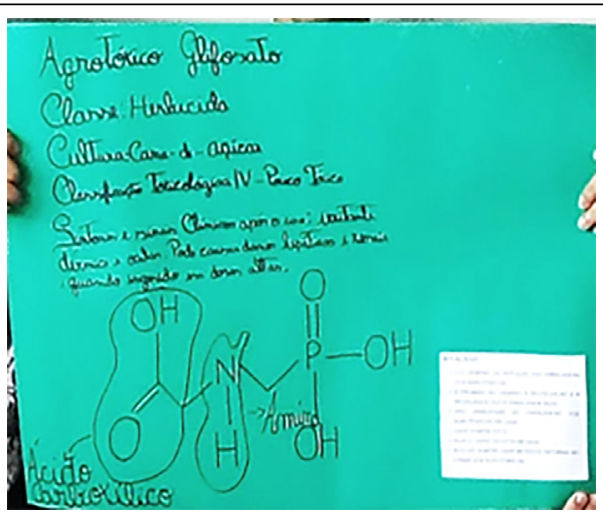

Fonte: Elaborado pelo autor (2019). 
direcionados à sala de TV e assistiram a uma entrevista realizada pela autora da pesquisa com o "Agricultor B" que sobrevive do cultivo da cana-de-açúcar na região. Proporcionamos aos estudantes, através do vídeo, a reflexão de que os problemas na comunidade existem, desafiando-os não somente a melhor compreendê-los, mas a atuar com o fim de transformá-los.

Como forma de avaliar a aprendizagem, os educandos desenvolveram um texto intitulado: "A temática "Agrotóxico" facilitou a compreensão das funções orgânicas e dos riscos do uso inadequado desses produtos químicos?". Observa-se nas redações (Figura 1) que o contexto serviu para o desenvolvimento do conceito numa perspectiva freireana. Em termos práticos e de aprendizagem, os alunos se tornam multiplicadores em seu próprio lar e compreendem a necessidade de ler os rótulos e bulas na tomada das decisões sobre o uso correto dos defensivos agrícolas. É por meio destas e outras atividades que a disciplina cumpre com seu dever social.

A redação dos educandos, apesar de conter erros ortográficos, apresenta-se de forma crítica e percebe-se a construção de conceitos químicos. O descrito pela estudante em sua redação (Figura 1) reforça a importância da intervenção didática com um contexto próximo dos estudantes. Os noticiários têm informado sobre a liberação de muitos agrotóxicos banidos na Europa e em outros lugares do mundo, e a própria aluna se posiciona contra as decisões do governo. Apesar de nenhum momento da atividade tender politicamente, "não é possível pensar em linguagem sem ideologia e poder"
(Freire, 2005, p.16). Nesse sentido, aguçamos um imaginário crítico e reflexivo acerca da problemática. Dessa forma, a aluna deixa de ser uma mera receptora de informações para se transformar na construtora de seus próprios conhecimentos, os quais devem se tornar, necessariamente, relevantes para a vida dessa aluna (Brasil, 2006). A realidade em que a aluna vive foi transformada pela emancipação social, cultural e política desta classe social excluída pela inferiorização de uns para garantir a dominação de outros.

Todavia, as compreensões diante das mudanças reais que ocorrem no âmbito da saúde e ambiente no Brasil são de extrema relevância para que possamos entender as dinâmicas que operam sobre máquinas e configurações da agricultura, ora dita industrializada, principalmente nas zonas rurais, onde a necessidade de se obter renda e subsistência evidencia um processo de exposição das famílias campesinas, e consequentemente suas formas tradicionais de produzir. Com isso, incorporados por uma lógica pautada na produtividade, os camponeses fazem uso indiscriminado de agrotóxicos nas lavouras e não possuem nenhum acompanhamento técnico efetivo das secretarias municipais da agricultura, ou de qualquer outro órgão que atue na área (Silva, 2016). Então, para superar a situação de oprimido, o processo educativo deve ser considerado como prática da liberdade pela dialogicidade, focada na interlocução entre educador e educando (Freire, 2008). É importante reconhecê-los como sujeitos de uma outra pedagogia e dialogar através de suas identidades e histórias.
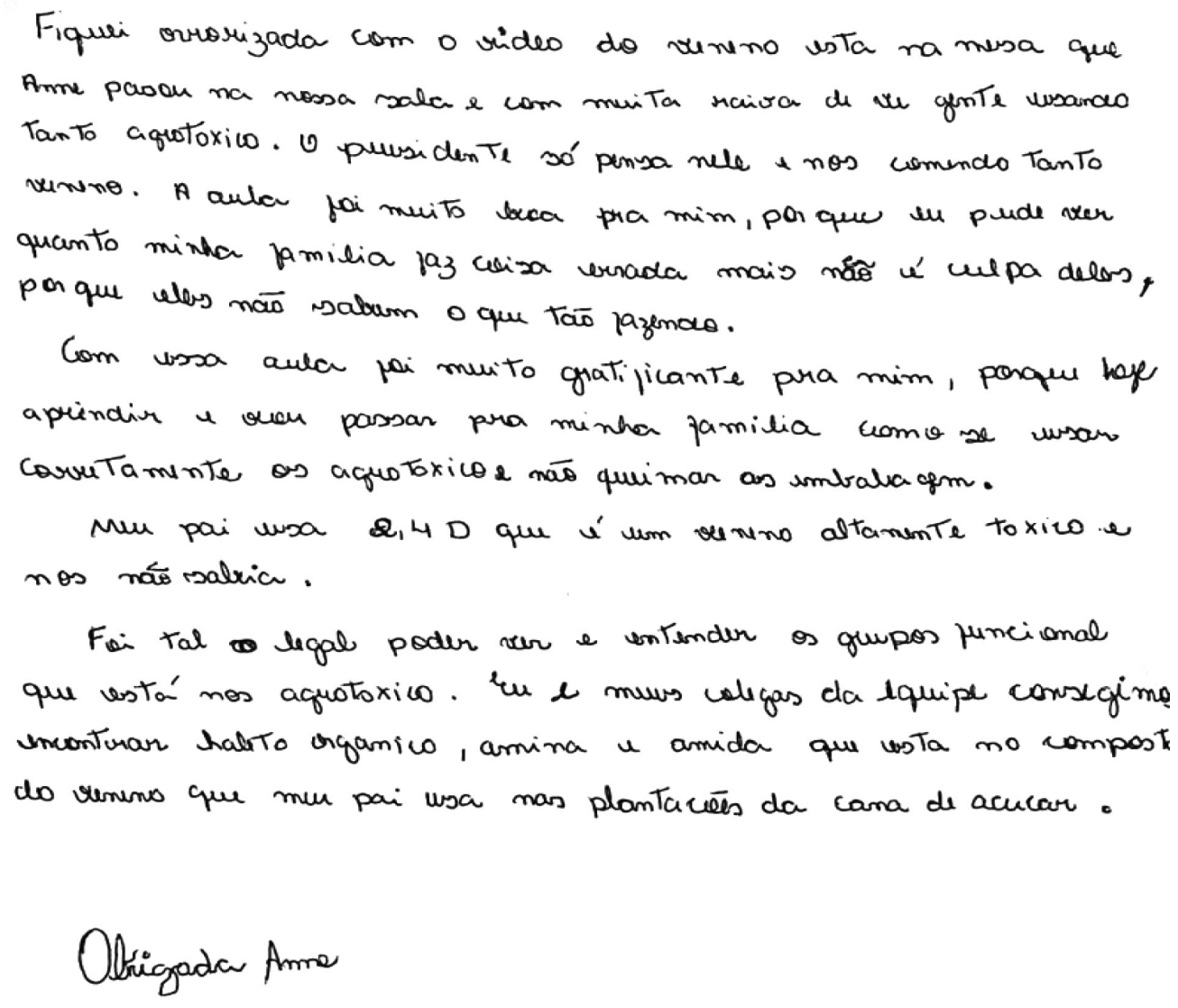

Figura 1: Produção textual de A14 sobre a temática. 
Outro componente da destruição do ciclo ecológico são as influências que as bancadas ruralistas têm nas produções legislativas, bem como sua presença nas direções de órgãos executivos, a exemplo do MAPA (Ministério da Agricultura, Pecuária e Abastecimento), imprimindo um descontrole nas medidas de proteção à saúde e ao ambiente, por meio de diretrizes e ações na contramão do que ocorre no resto do mundo. Seria obrigação do Estado, seja por meio de suas secretarias ou técnicos especializados, um exercício de fiscalização para trazer segurança a quem faz a aplicação do produto, haja vista que crianças e adolescentes se submetem rotineiramente a condições que permeiam a atividade de plantio junto a seus pais e, como tal, também se expõem às consequências do uso indevido ou irregular.

No Quadro 9 estão as categorizações das produções textuais, desenvolvidas pela técnica da análise textual discursiva (ATD).

Foram construídas sete categorias, a saber: facilitação do aprendizado científico; desenvolvimento do contexto social; formação de pensamento crítico; importância da leitura dos rótulos; perigos para a saúde; uso de EPI's; e ações para evitar contaminação. As categorias não são divergentes, expressam a saída da sub-humanidade e a subcultura e se coadunam para um conhecimento escolar que se articulou com a realidade. Assim, a educação se estabeleceu como elemento de transformação, como mostram as unidades de significados. Nesse sentido, é perceptível que a escola entende a realidade que os estudantes vivem pela temática abordada e estabelece uma educação integral, ou seja, incorporam os indivíduos em sua totalidade através da química dos agrotóxicos. Nesse contexto, a formação dos alunos foi para a cidadania.

Por conseguinte, conforme as produções textuais da Figura 3 e do Quadro 9, percebe-se que os estudantes conseguiram relacionar o conteúdo de funções orgânicas com os agrotóxicos, bem como socializaram com a comunidade escolar o conhecimento adquirido durante o desenvolvimento da pesquisa. Atitudes como comentar com os familiares e vizinhos sobre como utilizar corretamente os agrotóxicos mostram que esses alunos foram estimulados durante a pesquisa a serem multiplicadores dos conhecimentos. Essas são experiências reais que exigem uma proposta pedagógica dialógica e plural.

Através do conhecimento de problemas sociais, o estudante é instigado a participar ativamente da sociedade, tomando decisões que influenciam na melhoria de sua qualidade de vida e mudam suas atitudes em relação ao ambiente, bem como desenvolvem postura crítica e reflexiva para melhorar as operações de cultivo da comunidade local e passam a ser sujeitos de direitos. O papel do educador no processo de ensino e aprendizagem nesta pesquisa foi, conforme prega Freire, o de compartilhar experiências com o aluno para construção do conhecimento, no papel de mediador, ajudando no despertar de uma consciência crítica da realidade (Freire, 2008).

Quadro 9: Unidades de conhecimento produzidas através da ATD

\begin{tabular}{|c|c|c|}
\hline Categoria & Unitarização & Unidades de Significados \\
\hline $\begin{array}{l}\text { Facilitou aprender } \\
\text { cientificamente }\end{array}$ & Funções Orgânicas & $\begin{array}{l}\text { ".. conseguimos encontrar haleto orgânico, amina e amida no veneno." } \\
\text { "...aprender a encontrar com mais facilidade as funçôes orgânicas presentes em } \\
\text { alguns agrotóxicos que as famílias de meu amigo usam." }\end{array}$ \\
\hline $\begin{array}{l}\text { Desenvolvimento do } \\
\text { contexto social }\end{array}$ & Contextualização & $\begin{array}{l}\text { "Antes eu não conseguia entender como a função do álcool por exemplo pode } \\
\text { tá presente no meu dia a dia..." } \\
\text { "Achei mais fácil de entender e ver funções orgânicas nos produtos usados no } \\
\text { meu dia a dia. Achava muito difícil imaginar e entender essas funções." }\end{array}$ \\
\hline $\begin{array}{l}\text { Formação de aprender } \\
\text { a pensar }\end{array}$ & Posicionamento & $\begin{array}{l}\text { "...apreendi e vou passar pra minha família como se usar corretamente os agro- } \\
\text { tóxicos e não queimar as embalagens." } \\
\text { "...porque eu vou falar com meus visinhos que usam para poder usar correta- } \\
\text { mente." }\end{array}$ \\
\hline $\begin{array}{l}\text { Importância da leitura } \\
\text { dos rótulos }\end{array}$ & $\begin{array}{l}\text { Classificação } \\
\text { toxicológica }\end{array}$ & $\begin{array}{l}\text { "A gente não sabia sobre as classificações toxicológicas..." } \\
\text { "Meu pai usa 2,4 D que é um veneno altamente tóxico e nós não sabia." }\end{array}$ \\
\hline Intoxicação & $\begin{array}{l}\text { Prejudicial à saúde } \\
\text { humana }\end{array}$ & $\begin{array}{l}\text { "...podemos até morrer." } \\
\text { "...pois prejudica toda a família..." }\end{array}$ \\
\hline Uso de EPI's & Manejo correto & $\begin{array}{l}\text { "...é muito importante o uso de EPIS durante o plantio do alimento para que não } \\
\text { fiquem doentes..." } \\
\text { "... o agricultor tem que se proteger usando os EPIS..." }\end{array}$ \\
\hline Prevenir contaminação & Conscientização & $\begin{array}{l}\text { "As roupas que a gente utiliza com o veneno minha mãe lava junto com as roupas } \\
\text { da familia e hoje sei que não pode." } \\
\text { "...embalagens vazias do veneno não pode ser guardada em casa e nem quei- } \\
\text { madas e nem dar pra outra pessoa." } \\
\text { "...lê a bula que vem dentro das caixas para ter mais cuidado no manejo com } \\
\text { esses venenos." }\end{array}$ \\
\hline
\end{tabular}

Fonte: Elaborado pelo autor (2019). 


\section{Conclusão}

Constatou-se que a investigação acerca da realidade dos alunos, no que se refere a sua situação de vida individual e social, através da entrevista desenvolvida com os agricultores da comunidade local, antes das aplicações das atividades na escola, facilitou o ensino e a aprendizagem dos discentes, pois as práticas relativas às atitudes de risco ali adotadas faziam parte do cotidiano desses estudantes, dando sentido também ao conhecimento da presença de grupos funcionais nas moléculas dos agrotóxicos utilizados, conduzindo a alfabetização científica.

O tema gerador da investigação foi um elemento importante para a necessidade de apreender as situações da vivência desses alunos, contendo as contradições. Delas surgiram as inquietações que envolvem situações significativas do contexto da comunidade na qual a escola é inserida. Nesse sentido, a temática se mostra muito valiosa, por ter grande potencial social e educacional, promovendo nos discentes a ponderação crítica acerca da importância do assunto, conscientizando-os sobre a necessidade de uso correto dos agrotóxicos e os perigos oferecidos por eles quando mal utilizados.

Sendo assim, foi possível, no decorrer da pesquisa e posterior análise dos resultados, alcançar o objetivo do presente trabalho, consistindo em ensinar o conteúdo de funções orgânicas de forma empírica, através do referencial freireano do tema social agrotóxico. Dessa forma, a educação foi conduzida para transformação social, na qual as ideias de Paulo Freire contribuíram para a articulação do conhecimento científico aos fatos direcionados ao cotidiano do educando.

\section{Referências}

ABREU, J. B. Agrotóxicos: usá-los ou não? Um estudo de caso no ensino de ciências. Ensino de Ciências e Tecnologia em Revista, v. 5, p. 19-34, 2015.

ANDRADE, F. Agrotóxico e agricultura- uma abordagem socioambiental reflexiva no ensino de química, Dissertação (Mestrado Profissional em Formação de Professores) Universidade Estadual da Paraíba, Pró-Reitoria de Pós-Graduação e Pesquisa, 2018.

AULER, D.; DALMOLIN, A. M. T. e FENALTI, V. S. Abordagem Temática: natureza dos temas em Freire e no enfoque CTS. Revista Alexandria, v. 2, p. 67-84, 2009.

BALICA, M. E. P.; SILVA, M. M.; SILVA, J. M.; ANDRADE, L. B. e JULIÃO, M. S. S. Agrotóxicos: uma proposta de abordagem para o ensino aprendizagem de Química no ensino médio. In: III CONGRESSO NACIONAL DE EDUCAÇÃO CNEDU, 3. 2016, Campina Grande. Anais..., Campina Grande: Realize Editora, 2016. Disponível em: https://www.editorarealize. com.br/index.php/artigo/visualizar/20175. Acesso em out. 2019.

BRAIBANTE, M. E. F. e ZAPPE, J. A. A Química dos Agrotóxicos. Química Nova na Escola, v. 34, p. 10-15, 2012.

BRASIL - Ministério da Educação. Parâmetros Curriculares Nacionais: Ciências Naturais. Brasília, DF: MEC/SEB, 2006.

CASSAL, V. B.; AZEVEDO, L. F.; FERREIRA, F. P.; SILVA, D. G. e SIMÃO, R. S. Agrotóxicos: uma revisão de
O estudo e desenvolvimento das atividades proporcionaram aos estudantes e à comunidade escolar uma reflexão pautada na utilização dos agrotóxicos sobre as práticas agrícolas utilizadas na região de Divina Pastora. Essa intervenção se deu por meio da provocação da necessidade de ler os rótulos e bulas desses defensivos para saber como manuseá-los corretamente. É importante salientarmos que é preciso uma responsabilidade por parte dos poderes públicos, porém, sem eximir a sociedade, a escola e as instituições da tarefa de formar e informar sobre pelo menos os três eixos do agrotóxico: o uso, o descarte e os efeitos colaterais da aplicação inadequada.

\section{Nota}

1PESSANHA, L. D. R. O sentido brasileiro da segurança alimentar: mundo rural e cultura. Rio de Janeiro: Mauad, 2002, p. 263-284.

Anne Caroline Carvalho Santos (aninhacarvalhoufs@ hotmail.com), licenciada em Química pela Faculdade Pio Décimo. Aracaju, SE - BR. Amélia Bastos de Souza (amelia.bastos29@bol.com.br), licenciada em Química pela Faculdade Pio Décimo. Aracaju, SE - BR. Thales Santos Silva (thalesjsilva1998@gmail.com), aluno de Iniciação Científica pela FAPITEC em abordagens interdisciplinares na área jurídica, educando da Faculdade Pio Décimo em Direito. Aracaju, SE - BR. Maria Clara Pinto Cruz (clara_aju@yahoo.com.br), graduada em Química Industrial pela Universidade Federal de Sergipe, licenciada em Química pela Faculdade Pio Décimo, mestra em Química e doutora em Engenharia Química, ambos pela Unicamp. Atualmente é professora no curso de Licenciatura em Química da Faculdade Pio Décimo e professora do Estado de Alagoas em Penedo. Aracaju, SE - BR.

suas consequências para a saúde pública. Revista Eletrônica em Gestão, Educação e Tecnologia Digital, v. 18, p. 437-445, 2013.

CASTRO NETO, N.; DENUZI, V. S. S.; RINALDI, R. N. e STADUTO, J. A. R. Produção orgânica: uma potencialidade estratégia para a agricultura familiar. Revista Percurso, v. 2, p. 73-95, 2010.

CAVAlCANTI, J. A.; FREITAS, J. C. R.; MELO, A. C. N. e FREITAS FILHO, J. R. Agrotóxicos: uma temática para o ensino de química. Química Nova na Escola, v. 32, p. 31-36, 2010.

CORRÊA, D. M. Agrotóxicos: propostas diferenciadas para o tema em escolas do campo no município de Dom Pedrito-RS. Monografia (Especialização em Educação do Campo e Ciências da Natureza). UNIPAMPA, Dom Pedrito, 2017.

DELIZOICOV, D. Concepção problematizadora do ensino de ciências na educação formal: relato e análise de uma prática educacional na Guiné Bissau. Dissertação (Mestrado em Ensino de Ciências) - Instituto de Física, Universidade de São Paulo, São Paulo, 1982.

DELIZOICOV, D. La educación en Ciencias y la perspectiva de Paulo Freire. Alexandria: Revista de Educação em Ciência e Tecnologia, v.1, p.37-62, 2008.

FRANCISCO JR., W. E.; FERREIRA, L. H. e HARTWIG, D. R. Experimentação Problematizadora: Fundamentos Teóricos e Práticos para a Aplicação em Salas de Aula de Ciências. Química Nova na Escola, n. 30, p. 34-41, 2008. 
FREIRE, P. Pedagogia da Autonomia: Saberes necessários à prática educativa, 33 ${ }^{\mathrm{a}}$. ed. Rio de Janeiro: Paz e Terra, 2005.

FREIRE, P. Pedagogia do Oprimido. Rio de Janeiro: Paz e Terra, 2008.

FUNASA - Guia de vigilância epidemiológica. Brasília: Ministério da Saúde, 1998.

IBGE. Levantamento sistemático da produção agrícola (LSPA). Disponível em: ttps://www.ibge.gov.br/estatisticas-novoportal/ economicas/agricultura-e-pecuaria/9201-levantamentosistematico-daproducao-agricola.html, acesso em out. 2019.

KRAUSHAAR, A. e ROSKOSZ, K. A. Concepções de estudantes do ensino médio sobre agrotóxicos e transgênicos. $V$ Simpósio Nacional de Ensino de Ciência e Tecnologia, p. 1- 12, 2016.

LIMA, A. M. e MOZZER, N. B. Análise do entendimento conceitual em uma sequência didática sobre o uso de pesticidas fundamentada na modelagem analógica. Química Nova na Escola, v. 41, p.82-97, 2019.

MELLO, L. F.; FONSECA, E. M. e DUSO, L. Agrotóxicos no ensino de química: proposta contextualizada através de um jogo didático. Revista eletrônica Ludus Scientiae, v. 2, p. 76-90, 2018.

MORAES, P. C.; TRAJANO, S. C. S.; MAFFRA, S. M. e MESSEDER, J. C. Abordagem Agrotóxico no Ensino de Química: Uma revisão. Revista Ciências \& Ideias, v. 3, p. 1-15, 2011.

MORAES, R. e GALIAZZI, M. C. Análise textual discursiva: processo reconstrutivo de múltiplas faces. Ijuí: Editora Unijuí, 2006.
MORO, B. P. Um estudo sobre a utilização de agrotóxicos e seus riscos na produção do fumo no município de Jacinto Machado/ SC. Monografia. Unesc, Criciúma, 2008. Disponível em: http:// www.bib.unesc.net/biblioteca/sumario/000038/0000380C.pdf. com, acesso em out. 2019.

PERES, F. Saúde, trabalho e ambiente no meio rural brasileiro. Revista Ciência. Saúde coletiva, v.14, p. 1995-2004, 2009.

PERES, F. e MOREIRA, J. É veneno ou é remédio? Agrotóxicos, saúde e ambiente. Rio de Janeiro: Editora Fiocruz, 2003.

SANTOS, W. L. P. e SCHNETZLER, R. P. Função social: O que significa ensino de química para formar o cidadão? Química Nova na Escola, v. 4, p. 28-34, 1996.

SILVA, C. M. M. e FAY, E. F. Agrotóxicos e ambiente. Brasília: Embrapa Informação Tecnológica, 2004.

SILVA, P. A. S. Transformações na organização produtiva da agricultura camponesa: um estudo da produção de abacaxi de Sergipe. Dissertação (Mestrado em Geografia) - Programa de Pós-Graduação em Geografia - PPGEO, Universidade Federal de Sergipe, 2016.

SIMÕES, N. T. e ALVES, E. F. O uso da temática agrotóxico no ensino de química orgânica através da metodologia dos momentos pedagógicos. Revista Debates em Ensino de Química, v. 4, p. 6-19, 2018.

SOUZA, M. M. O. e FOLGADO, C. A. R. Agrotóxicos e Agroecologia: enfrentamernto científicos, jurídicos, políticos e socioambientais. Anapólis: Ed. UEG, 2019.

Abstract: The invasion of pesticides in agriculture: an approach to the study of organic functions in a Freirean perspective of education in a rural school. This research aimed at studying the context of "pesticides" as a social theme and the content of organic functions by using the Freirean framework adapted to formal education. The methodological procedure consisted in Delizoicov's three pedagogical moments adjusted to Paulo Freire's ideas. The problematization started with a survey with farmers from the region where the school is located, followed by a debate with students over a video about agrotoxics. In the knowledge organization moment, a class on organic halides and nitrogenated functions was given, developing the contextualization. In the application of knowledge moment, the main functional groups present in the pesticides used in that region were identified. Textual productions were developed as analytical data. For the diagnosis of the data, the Discursive Textual Analysis was used. It was observed that the Freirean perspective transformed the concrete reality in which the students live by social, cultural and political emancipation. In this sense, recognizing them as subjects of another pedagogy and dialoguing about their identities and stories made all the difference. School knowledge was articulated with reality and education was established as an element of transformation through scientific literacy on the chemistry of pesticides.

Keywords: Pesticides, contextualization, organic functions. 